\title{
O DESENVOLVIMENTO ESCOLAR SIGNIFICATIVO DO ALUNO SURDO ATRAVÉS DA LIBRAS - (LÍNGUA BRASILEIRA DE SINAIS)
}

\author{
Sonia Alves dos Santos silva ${ }^{1}$
}

RESUMO: O trabalho desenvolvido e apresentado a seguir, propõe uma breve e compreensível abordagem sobre as práticas pedagógicas, observando seus aspectos, sua prescrição em relação à lei de diretrizes e bases, assim como, uma passagem pelo universo da cultura SURDA, observando as interações por meio da comunicação em libras e a observar o comportamento do educando surdo, isso no ambiente escolar e no desenvolvimento humano. E o processo de alfabetização do mesmo. Tendo neste a importância da aprendizagem em Libras. (Língua Brasileira de Sinais), mas com ênfase no desenvolvimento pleno, desde o diagnostico até a formação pessoal e social. Demostrando também a formação docente em meio inclusivo nos dias atuais e a importância de estar preparados para que a aprendizagem do surdo aconteça.

Palavras-chave: Libras. Desenvolvimento cognitivo. Aprendizagem.

\section{INTRODUÇÃO}

Este artigo foi elaborado a partir de discussões e reflexões teóricas realizadas no decorrer do curso de Pós-graduação para obtenção de certificação da formação em Libras. O estudo foi desenvolvido no formato de artigo científico, na modalidade relato de experiência e tem como objetivo estabelecer relações entre as teorias, estudadas, com as experiências adquiridas no decorrer do curso. Assim, busca interpretar por meio de textos, discussões e reflexões teóricas o desenvolvimento em contextos educacionais que enfatizam a aprendizagem da Libras. E o desenvolvimento da habilidade em Língua de sinais.

A escolha deste tema, para o presente Trabalho de Conclusão de Curso (TCC) iniciou com as reflexões obtidas no decorrer da formação nas aulas e explicações dos maravilhosos professores e vivências cientificas embasadas no conhecimento de cada módulo estudado e ao adquirir de forma simultânea e reflexiva nos estudos acadêmicos e nas bibliografias disponibilizadas na grade curricular do mesmo. Sendo assim um ponto de partida para o desenvolvimento e análise do conhecimento adquirido para que sejam

\footnotetext{
I Pós-graduação em Libras, FAVENI. E-mail: prof.soniasurdez@hotmail.com. 
descritos e analisados neste para avaliação de nossa capacidade docente e eficaz para o âmbito educacional ao qual direcionamos nossos estudos para o desenvolvimento e aprendizagem do aluno surdo através da Libras.

E ao se abordar, discutir ou propor todo e qualquer diálogo sobre a educação brasileira em Libras, podemos esperar uma gama diversa de temas a serem postos em pauta, pois, tal temática nos direciona a uma reflexão sobre alguns setores que necessitam de uma atenção, assim como, uma reflexão acerca de pontos que podem ser melhorados com didáticas eficazes e concretas e resultados nítidos do desenvolver de nossos trabalhos e estudos até aqui realizados para que de forma sistematizada, significativa, prazerosa ao estarmos preparados para permear o universo educacional com nossa profissão de educador com aprendizagem em Língua Brasileira de Sinais. E através dessa se reformular a tais métodos de adquirir o conhecimento em uma prática afetiva e conceituada com pesquisas e formações continuadas de agora para frente no contexto escolar e vivência diária da profissão que seguiremos em educação de surdos com os conhecimentos adquiridos através dos grandes mestres que em nossa vida passaram e ilustres exemplos que levaremos para toda a vida profissional. De forma visual e significativa. E que o educador não pode ser limitado no processo de aprendizagem e formação continuada, buscando estratégias educacionais especificas para o processo de aprendizagem.

Este artigo cientifico nos leva a compreender o paradigma da educação de surdos e a importância de percorrer pelo histórico da aprendizagem em Libras pelo aluno e a vivência e experiência do educador em sua função e mediação em sala de aula. Sendo possível perceber que a Libras é a língua natural dos surdos e que a mediação entre aluno e educador se faz necessário uma comunicação significativa. E para que isso aconteça, o educador precisa se esforçar para aprender a se comunicar com o aluno surdo e isso com conhecimentos sistematizados e a busca cientifica sistematizadas com materiais confeccionados na língua de sinais, sendo jogos, e atividades lúdicas e preparadas na língua da criança em novos conceitos e percepções educativas renovadas e significativas com o lúdico. E com aprendizagem inclusiva. Assim sendo:

[...] A educação lúdica é uma ação inerente na criança e parece sempre como forma transacional em direção a algum conhecimento, que se define na elaboração 
constante do pensamento individual em permutações constantes com o pensamento coletivo [...] (ALMEIDA, 1995. P II)

Com tudo, toda atividade aplicada pelo professor dentro e fora de sala, no exemplo de brincadeiras no parque, são formas de promover o desenvolvimento de forma total das crianças, concretizando assim, o dito por Almeida na citação a cima, o brincar é da criança por natureza, somado as atividades coletivas, definem o lúdico, como também, o coloca como um dos meios mais eficientes de construção e formação cognitiva, motora, social, política e cultural que demonstram o processo de aprendizagem de cada ser no contexto educativo e coletivo. O que se torna eficaz para o crescimento e amadurecimento das assimilações adquiridas no convívio escolar e na mediação comunicativa, no caso em Libras, a primeira língua do surdo.

Também é indispensável garantir que a criança use sua imaginação, para permitir que aflore essa capacidade do ser humano, deve-se permitir que os momentos de atividade recreativa decorram de forma natural, espontânea, não excluindo a comunicação na língua natural do aluno surdo, no perímetro escolar ou de seus responsáveis no extra escolar, sempre mantendo a cautela para não interferir de forma desnecessária para que não limite o desenvolvimento criativo e social da criança. Esse cuidado faz com que a criança se desenvolva de forma sadia e não venha a perder a inocência de criança e que o conhecimento tem etapas a serem vividas, não devendo ao adulto antecipar ou pular fases de desenvolvimento e sim deixar que a criança vivencie e descubra por si só as etapas significativas do conhecimento e desenvolvimento individual de cada uma, pois aprendemos de forma única e individual por meio de comunicação e interação em uma cultura em que estamos inseridas.

É importante que o professor valorize as interações estabelecidas em sala de aula, ressaltando a efetivação do vínculo do professor com seus alunos, que ele conheça e reconheça o outro, definindo critérios no contexto social. Cabe ao professor estabelecer relação com o outro, seguido de princípios de igualdade e valores universais de acordo com objetivos e conteúdos propostos para os alunos e de suma importância que o professor seja criativo e que a cada comportamento das crianças mostram o desenvolvimento que as mesmas precisam, assim sendo, o profissional tem que ter um olhar atento para observar as 
necessidades de desenvolvimento nas comunicações em grupo ou individual e nos espaços escolares. O profissional também deve estimular á família à importância da comunicação da criança com a família na Língua natural da criança com o desenvolver, e mostrar também que o afeto desenvolve e estimula o cognitivo para aquisição das línguas envolvidas.

Freire (2006, P.103) ressalta que, tão importante quanto o ensino dos conteúdos, é o testemunho ético ao ensiná-lo. É a decência com quem se faz. É a preparação científica revelada sem arrogância, pelo contrário, com humildade. Ainda de acordo como autor, (Freire2006, p.33) o caráter formativo implica no respeito á natureza do ser humano, e os conteúdos que são ensinados devem estar aliados a uma formação moral, pois enfatiza que ensinar é substantivamente formar e que essa formação é feita por construções do dia a dia e de momentos significativos para assimilar e se desenvolver, os sentimentos e afetos são favoráveis para a significante aprendizagem de valores educativos que permeiam a vida humana em sua aprendizagem cotidiana e na base que são as primeiras aprendizagens. Por isso os educadores devem ensinar e direcionar o desenvolvimento e aprendizagem nos primeiros anos de vida.

Por fim, sabe-se que haverá desafios futuros na área da educação para que os

educadores tenham uma formação continuas e eficaz no processo de comunicação, para assim direcionar a aprendizagem para com os surdos para está e para as próximas gerações que serão desafios com necessidades de se promover respostas adequadas para preencher as lacunas que são naturais, pois, com o decorrer dos anos, a as mudanças trazem a necessidade de se evoluir e de se adaptar sendo realmente algo a se pensar e a estudar para que os educadores não se percam nesse meio campo, que tenham muito cuidado na aquisição de conhecimento e que sejam pesquisadores e inovadores em suas didáticas se tornando profissionais apaixonados pela profissão e que façam a diferença na vida dessas crianças e de toda a sociedade em um processo de construção e desenvolvimento humano e escolar na aquisição comunicativa em todas as línguas envolvidas com aprendizagem significativa e valorização da cultura linguística envolvida, pois com os estudos da formação foi possível perceber que os surdos usam as línguas de sinais para se comunicarem e a se desenvolverem como pessoa em sua cultura pessoal e social. 


\section{FUNDAMENTOS TEÓRICOS}

No Brasil, o Estatuto da Criança e do Adolescente, protege e busca garantir à criança o direito de se expressar, interagir e se comunicar por meio de brincadeiras, ou seja, até mesmo a própria Constituição Federal de 88 garante tais momentos de socialização, que prever como direito fundamental da pessoa humana, o direito ao laser sendo analisado de forma efetiva, pois é em sociedade que os seres humanos se desenvolvem sua linguagem, as primeiras aquisições de oralidade e vocabulários e passam a serem vistos como seres de direitos de construção da autonomia própria e do ouvir e respeitar ao próximo. Cabe ao educador e aos adultos do meio essa mediação e observação do desenvolvimento infantil, da criança e do adolescente em suas etapas de vida para que cresçam de forma saudável e eficaz no desenvolvimento pleno no processo de comunicação.

Ainda sobre a importância da manutenção e, de se proporcionar esse contato entre um ou vários grupos de crianças, é possível reafirmar que é por meio da comunicação e interações que são formados alguns processos culturais, sendo que, os sujeitos tendem a absorver alguns conhecimentos que foram construídos, formados ou desenvolvidos por seus antepassados, pelas gerações anteriores e assim por diante. E o educador é muito importante nessa mediação de construção do conhecimento e desenvolvimento desde infantil em análise da criança já traz de casa os primeiros índices e esse observar e mediar conhecimentos faz com que se desenvolva com segurança e a aprendizagem permaneça e evolua para as etapas seguintes do desenvolvimento infantil e humano.

A partir disso, por isso, pode-se afirmar que a socialização é elemento indissociável a criança, pois incide diretamente na transformação de cada um, somado a isso, observe:

\footnotetext{
$\mathrm{Na}$ construção das funções superiores (pensamento, linguagem, criatividade, imaginação), a brincadeira é muito importante de ser estudada, não só porque representa o primeiro momento na construção da imaginação, mas também porque dá origem a vários processos psicológicos fundamentais ao desenvolvimento da criança (VIEIRA; CARVALHO; MARTINS, 2005, p. 40).
}

E, nesse momento é pertinente voltarmos a referir às primeiras expressões de comunicação exercidas pelas crianças ao iniciarem a vida escolar, sendo que a partir dessa etapa da vida, elas começam a conhecer o mundo de forma mais filosófica, além de novas aprendizagens, a curta bagagem que possuem passa por uma redefinição devido à relação 
com o outro ser, a outra criança ou, crianças, com aspectos em partes distintas, seja social, religiosa, política ou cultural.

Podemos assim destacar o que afirma LEONTIEV:

Em toda sua atividade e, sobretudo, em seus jogos, que ultrapassaram agora os estreitos limites da manipulação dos objetos que a cercam, a criança penetra um mundo mais amplo, assimilando-o de forma eficaz. Ela assimila o mundo objetivo como um mundo de objetos humanos reproduzindo ações humanas com eles. Ela guia um "carro", aponta uma "pistola", embora seja realmente impossível andar em seu carro ou atirar com sua arma (LEONTIEV, 20orb, p. 59)

E, por essas e outras afirmativas, nota-se que tais atividades relacionadas anteriormente, ganharam destaque e força devido à comprovada eficiência e bem feitorias na construção de vários aspectos relacionados ao desenvolvimento cognitivo, biológico, físico, social e cultural da criança, assim, o lúdico, a pedagogia, proporcionam interação, são ferramentas indispensáveis para o processo de aprendizagem de crianças e adolescentes, uma vez que, as relações sociais seguem constantemente por toda vida.

Por isso, existe a necessidade de que o educador entenda que sua atuação vai além de ensinar regras, sinais soltos e palavras, o ensino em seu significado é amplo e está ligado de maneira indissolúvel à formação de um ser humano, que fará parte de um complexo mecanismo de sobrevivência em coletividade, e que esse ser é peça fundamental para o futuro de uma sociedade que sem princípios, moral, ética, respeito, educação e empatia, caminhará para ser realmente seu próprio lobo. Além disso, destaca-se a importância educadora materializar o objeto de ensino, e também esclarecer, aplicar de forma simples e objetiva o que está presente nos planos de ação educacional de forma ampla e inclusiva que atenda a todos nas línguas envolvidas no ambiente escolar.

Por tanto, destaco uma ótica voltada à necessidade de se enxergar as práticas da adaptação com sua devida importância, pois é uma ferramenta bastante positiva não deixando dúvidas sobre sua eficiência, devidas também sua completude cognitiva, motora e psicossocial com as línguas envolvidas e o desenvolvimento da criança surda no espaço escolar. Sendo nesse caso: orais e viso espacial.

Assim, os meios utilizados pelos educadores no decorrer dos estudos observados, mostrou uma forma de desenvolvimento dos objetivos que foram planejados por meio de 
um segmento já pré-estabelecido em estudos dos módulos do portal acadêmico. Tornando assim a nossa aprendizagem bem produtiva e organizada. Por exemplo, uma forma de desenvolvimento e adaptação de conteúdo pode ser por jogos simbólicos e adaptados:

O jogo inclui características: simbolismo: representa a realidade e atitudes; significação: permite relacionar ou expressar experiências; atividade: a criança faz coisas; voluntario ou intrinsicamente motivado: incorporar motivos e interesses; regrado: sujeito e regras implícitas, e episódicas: metas desenvolvidas espontaneamente. (FROMBERG, i987, p.36 apud KISHIMOTO, i996, p. 27)

Dessa maneira, a aprendizagem através processo educacional planejado, organizado e supervisionado pelo educador, permitem várias articulações que resultam no desenvolvimento biológico e cognitivo da criança e, em decorrência disso, essa relação e método de ensinar o processo da fala e a comunicação em libras, vem se destacando e ganhando maior visibilidade, se tornando até um meio essencial de ensinar, uma vez que, a aprendizagem comunicativa é uma das primeiras formas de expressões de uma criança, principalmente na tua fase pré-escolar, exato momento em que se ocorrem várias alterações em seu desenvolvimento e na sua capacidade aprendizagem e os estímulos coerentes e significativos para o desenvolvimento pleno da comunicação das línguas envolvidas, no caso da criança surda, a língua portuguesa e a libras e essa mediação deve acontecer nas duas.

\section{CONSIDERAÇÕES FINAIS}

Em consequência do exposto, de todas as experiências estudadas, importante destacarem que as crianças sempre estão em convívio com a linguagem, pois através dele as crianças se desenvolvem e cria um universo de fantasias e faz de conta, nota-se que elas têm grande potencial em aprender de forma agradável e em seu tempo e o propiciar isso á infância é um dever dos educandos que são preparados para essa mediação do educar através da libras com materiais concretos e visuais para que ao visualizar, tocar, sentir, perceber, interagir desenvolver e a crescer de forma plena e consciente com sonhos, imaginação e fantasias da infância, processos que constroem o desenvolvimento infantil para um ser comunicativo com desenvolvimento nas línguas envolvidas e que usam no cotidiano em suas vivências e culturas. 
As crianças quando estão em espaço livre usavam sua imaginação, brincam com areia, os meninos constroem castelos e as meninas fazem bolos, usavam folhas e flores para decoração do mesmo, brincam de casinhas, de pega-pega, os meninos usam os chinelos para fazer a trave do gol quando jogam bola, algumas meninas brincam de cabelereiras e usam peças de brinquedos como o cortador de cabelo e com suas imaginações e criatividades criam e recriam em suas brincadeiras. Outras crianças entram e saiam de caixas, trabalhando a noção de espaços, de tamanhos, se cabiam seus corpinhos nas caixas ou não, com caixas de vários tamanhos. O empilhar latas e compararem a suas alturas, subir e a descer escadas, o cheio e o vazio com latas e areia. O calcar sapatos de diferentes tamanhos e a aprender a amarrar os cadarços, e foi muito lindo o cantinho de fantasias, com roupas de vários personagens e que as crianças se vestiam e contavam as histórias como se fossem os personagens com a oralidade em desenvolvimento, palavras, sorrisos e expressões de alegria e contentamento tudo isso com apontamento e expressões que mostrem a comunicação significativa como todas as crianças no ambiente escolar e infantil, sendo possível ensinar libras nas primeiras fases da vida infantil. Sendo as primeiras aprendizagens por apontamento e expressões comunicativas de forma com que a inclusão aconteça. Podendo observar e a descrever o ambiente em que trabalho, pois um deles é a educação infantil de o a 5 anos de idade. Inclusive nos bebês que predominam o apontamento e expressões significativas para o processo de comunicação do surdo no decorrer de suas habilidades comunicativas em formação.

Numa visão anteriormente, particular, havia uma conclusão de que a linguagem em crianças se desenvolvem e aprendem brincando, fácil percepção e sendo o brincar um momento organizado e que um conjunto diverso de brincadeiras para crianças, as leva ao processo de interação comunicativa e aprendizagem da cultura do meio, por isso, é preciso se ter um espaço bilíngue para que a aprendizagem flua e aconteça de verdade sem privação do momento de interação social natural da criança, ou interferência dessabida de qualquer pessoa, seja os pais ou até mesmo os profissionais da educação.

Assim, é pertinente afirmar que, a infância é um momento mágico de várias oportunidades para se desenvolvimento e, trabalhar a construção cognitiva, mas também, um período delicado, capaz de promover marcas que serão carregadas por uma vida toda, 
cabendo assim, ao pedagogo e, todo membro da sociedade, zelar pelo desenvolvimento, psicossocial, cultural, político, físico, educacional e humano daqueles que são o futuro da humanidade de forma significativa e com pessoas mais desenvolvidas, pois com o processo educacional mais revolucionário com significados eficazes e com o desenvolvimento mais humanizado ao percorrer a formação por completo de cada criança que se tornará pessoas mais desenvolvidas em seu cognitivo, com conhecimento mais claro da realidade, maturidade e ser humano mais pleno com afeto, entusiasmo pela vida conseguem e com o próximo e que acima de tudo terá a formação humana afetiva e com as emoções firmes para enfrentarem a realidade de vida com conhecimento, profissionalismo e com dignidade linguística.

Em decorrência das afirmações anteriores, obtidas por meio de leituras e pesquisas, nos asseguram concluir que devidos os fatos conhecidos, o método de ensinar por meio de brincadeiras adaptada, jogos e interações, o lúdico, possibilita que a educação infantil se promova numa maneira divertida de se conhecer várias experiências do mundo, seja social, biológica, cientifica, motora ou psicopedagógico nas mediações de conhecimento e aprendizagem humana, de forma eficaz, plena e consciente da didática aplicada, com soluções e resultados eficientes no desenvolvimento das crianças que observamos em nossa formação acadêmica, sendo um pilar em nossa vida, por caminhos diferentes que só descobrimos na formação e que anteriormente não os conhecíamos e que são brilhantes e trazem vida alegria, entusiasmo, e querer ser criança, chegando até mesmo a despertar a criança interior de cada um dos educadores profissionais que estamos sendo formados na cultura linguística.

Pois, segundo Violada (20II, p.I), através das atividades lúdicas, as crianças conseguem desenvolver a oralidade, foco, concentração, racionalidade e capacidades motoras, assim como, desenvolver características destaques, ou seja, possibilidade de despertar um potencial maior, de conhecer mais, fazendo crescer também a sua imaginação, o raciocínio mental e criatividade. Assim, Almeida (1994, p. 4I), explica que a educação lúdica, em sua base, além de contribuir diretamente na "construção" da criança e do adolescente, promove essa formação de maneira saudável, constante, considerando-se que dessa forma, conclui o mais alto nível de pratica democrático, no momento de investe na 
promoção do conhecimento e desenvolvimento através das línguas envolvidas no ambiente formativo.

Contudo isso somos gratos e gratificados com a formação em que estamos passando e que a cada dia só nos mostra o dom que temos para ensinar e aprender, estes que aprendemos com nossos formadores acadêmicos e grandes profissionais que injetaram em cada formando uma percepção de educação diferente e baseada a estudos profundos das mediações e conhecimentos adquiridos ao decorrer de nossos estudos, com grandes teóricos e formadores e preparados para brilhar como estrelas lapidadas pelos nossos grandes mestres e com futuros brilhantes para começarem a semear a aprendizagem adquirida em searas escolares de nossas profissões com o conhecimento bilíngue com aquisição da língua brasileira de sinais. (Libras). Nos conhecimentos teóricos, linguísticos e legislativos que a alavanca em pleno conhecimento do novo para uma nova postura de aprendizagem linguística no meio cultural de um país em que vivemos e nos portamos sua cultura e postura frente ao processo educar e aprender.

\section{REFERÊNCIAS BIBLIOGRÁFICAS}

ALMEIDA, Paulo Nunes De. Educação Lúdica: Técnicas E Jogos Pedagógicos. São Paulo: Loyola, 1995 .

BRASIL. Ministério Da Educação. Lei De Diretrizes E Bases Da Educação Nacional. Lei № 9.394 De Dezembro De 1996. Estabelece As Diretrizes E Bases Da Educação Nacional. Disponível em: Http://Portal.Mec.Gov.Br/Seesp/Arquivo/Pdf/Lei9394. Acesso em in de junho de 202I.

FRIGOTTO, Gaudêncio. Qualidade E Quantidade Da Educação Básica No Brasil: Concepções E Materialidade. Rio de Janeiro, 2012.

FREIRE, Paulo. Pedagogia Do Oprimido. Rio de Janeiro: Paz e Terra, 2014.

FREIRE, Paulo. Pedagogia da autonomia. Rio de Janeiro: Paz e Terra, 2006.

LEONTIEV, Alexis N. Uma contribuição à teoria do desenvolvimento da psique infantil. In. Vygotsky, Lev S. (et al.). Linguagem, desenvolvimento e aprendizagem. 6.ed. São Paulo: Ícone, 200Ib. p. 59-83. 
Secretaria de educação especial. O tradutor e interprete de língua brasileira de sinais e língua. Programa Nacional de Apoio à educação de surdos - Brasília: MEC; SEESP, 2004

O Interprete de Língua de Sinais no contexto de uma aula de alunos ouvintes. In: LACERDA, C. B. F. de. Góis, M. C. R. de (org.) SURDEZ: processos educativos e subjetividade. São Paulo: LOVISE, 2000.

QUADROS, R.M. de ( 1996 ) - A aquisição/aprendizagem da Língua Portuguesa (L2): O contexto da pessoa surda. Porto Alegre: PUCRS.

SOUZA, Eulina Castro de. A importância do lúdico na aprendizagem. 2015. Disponível em: http://www.seduc.mt.gov.br/Paginas/A-import\% $\mathrm{C}_{3} \% \mathrm{~A} 2$ ncia-do- $1 \% \mathrm{C}_{3} \%$ Acesso em II de junho de 202I.

VIEIRA, Therezinha; CARVALHO, Alysson; MARTINS, Elizabeth. Concepções do brincar na psicologia. In. CARVALHO, Alysson et.al. Brincar(es). Belo Horizonte: Editora UFMG, 2005. p. 29-50.

VIOLADA, Rosiane. Brincadeiras e jogos na educação infantil. 2014.

KISHIMOTO, Tizuco Morchida. Jogo, brinquedo, brincadeira e a educação. 7 ed. São Paulo: Cortez, 1996. 